\title{
PEMANFAATAN KULIT BUAH JERUK NIPIS (Citrus aurantifolia) SEBAGAI LARVASIDA Aedes aegypti INSTAR III
}

\author{
Evy Ratnasari Ekawati ${ }^{*}$, Setyo Dwi Santoso ${ }^{2}$, Yeni Retno Purwanti ${ }^{3}$ \\ ${ }^{1}$ Dosen Mikrobiologi, Fakultas Ilmu Kesehatan, Univ. Maarif Hasyim Latif Sidoarjo \\ ${ }^{2}$ Dosen Kimia, Fakultas Ilmu Kesehatan, Univ. Maarif Hasyim Latif Sidoarjo \\ ${ }^{3}$ Mahasiswa DIII Teknologi Laboratorium Medik, Fakultas Ilmu Kesehatan, Univ. Maarif Hasyim Latif \\ Sidoarjo \\ *E-mail : evysains@gmail.com
}

\begin{abstract}
DHF (Dengue) disease is transmitted through mosquito vectorAedes aegypti.One way to do control the Dengue vector is to use insecticide made from natural materials and is environmentally friendly with lemon peel extract (Citrusaurantifolia). This study aims to determine the effectiveness of extracts of lemon peel (Citrus aurantifolia) in killing the third instar larvae Aedesaegypti with various concentrations and time variations. This were an experimental laboratory researchs using various concentrations of extract limes peel (Citrusaurantifolia) 1\%, 2\%, 3\%, 4\%, 5\%, 6\%, and 7\% in which there 25 larvae Aedes aegypti and using a variation of 30,60, 90, 120,180,240,300, and 1440 minutes after contact with the extracts limes peel (Citrusaurantifolia). Effective concentration to kill larvae of Aedes aegypti by $50 \%$ ( $\mathrm{IC}_{50}$ ) was the concentration of $3.419 \%$.
\end{abstract}

Keywords : LarvaeAedes aegypti; extract lemons peel (Citrus aurantifolia).

\section{PENDAHULUAN}

Di Indonesia, nyamuk Aedes aegypti dan Aedes albopictus merupakan vektor demam berdarah, tetapi sampai saat ini yang menjadi vektor utama penyakit demam berdarah adalah nyamuk Aedes aegypti. Kedua jenis nyamuk tersebut biasanya aktif pada siang hari, dan nyamuk betina lebih suka menghisap darah manusia daripada hewan (Dantje, T.S., 2009, Haditomo, I. 2010).

Nyamuk Aedes aegypti mengalami metamorfosis sempurna, dengan stadium-stadium meliputi telur, larva, pupa dan nyamuk dewasa. Stadium telur, larva dan pupa hidup di dalam air, sedangkan nyamuk dewasa hidup di darat. Upaya pemberantasan demam berdarah dengue (DBD) meliputi peningkatan kegiatan surveilans penyakit dan vektor, diagnosis dan pengobatan dini, serta peningkatan upaya pemberantasan vektor penular penyakit demam berdarah dengue (DBD) (Pratama, B.A. 2009).
Bentuk pengendalian perkembangan nyamuk Aedes aegypti dapat dilakukan secaramekanik, biologi, kimia dan perubahan sifat genetik. Pengendalian yang popular hingga saat ini adalah pengendalian secara kimiawi dengan menggunakan insektisida, karena lebih efektif dan hasilnya cepat terlihat bila dibandingkan dengan pengendalian biologis. Namun, penggunaan insektisida mempunyai dampak negatif, antara lain pencemaran lingkungan, kematian predator, resistensi serangga sasaran, dapat membunuh hewan peliharaan, bahkan dapat meracuni manusia (Susana, D. 2003).

Pemberantasan larva merupakan kunci strategi program pengendalian nyamuk Aedes aegypti di seluruh dunia. Penggunaan insektisida sebagai larvasida merupakan cara yang paling umum digunakan oleh masyarakat untuk mengendalikan pertumbuhan vektor tersebut. Insektisida yaang biasa digunakan di Indonesia adalah abate. Penggunaan abate di Indonesia sudah sejak tahun 1976. Empat tahun kemudian, sekitar tahun 1980, 
temephos $1 \%$ (abate) ditetapkan sebagai bagian dari program pemberantasan massal nyamuk Aedes aegypti di Indonesia (Aradilla, A.S. 2009).

Penggunaan insektisida yang berulang dapat menambah resiko kontaminasi residu pestisida dalam air, terutama air minum. Temephos tidak dapat diguanakn secara oral, sehingga keberadaannya tidak diharapkan ada di dalam air minum. Hal penting lain yang perlu diperhatikan adalah biaya yang tinggi dari penggunaan pestisida kimiawi dan mundulnya resistensi dari berbagai macam spesies nyamuk yang menjadi vektor penyakit. Laporan resistensi larva nyamuk Aedes aegypti terhadap temephos sudah ditemukan di beberapa negara, seperti Brazil, Bolivia, Argentina, Kuba, French, Karibia dan Thailand. Selain itu juga telah dilaporkan resistensi larva nyamuk Aedes aegypti terhadap temephos di Surabaya (Aradilla, A.S. 2009).

Dengan adanya permasalahan di atas, maka perlu dilakukan penelitian mengenai bahan alternatif yang bersifat alami untuk mengatasi penyebaran nyamuk Aedes aegypti. Penggunaan larvasida alami memiliki beberapa keuntungan, antara lain degradasi yang cepat oleh sinar matahari, udara, kelembeban dan komponen alam lainnya, sehingga mengurangi resiko pencemaran tanah dan air. Larvasida alami memiliki toksisitas yang rendah pada mamalia, sehingga penggunaan larvasida alami memungkinkan untuk diterapkan pada kehidupan manusia (Novizan. 2002). Pemilihan bahan yang akan digunakan sebagai larvasida harus aman terhadap manusia ataupun organisme lain, selain itu bahan tersebut mudah diperoleh dan diharapkan dapat memberi dampak positif pada kesehatan manusia (Pratiwi, A. 2013).

Saat ini penelitian tentang tumbuhan yang berpotensi sebagai insektisida botani telah banyak dilapotkan. Wijaya (2008) meneliti tentang ekstrak biji kecubung (Datura mentel) yang mengandung alkaloiddan saponin bersifat larvasida terhadap larva nyamuk Aedes segypti. Selain itu, tumbuhan Ocinum gratidsimum yang mengandung eugenol bermanfaat sebagai larvasida terhadap nyamuk Aedes aegypti (Haditomo, I. 2010, Calvacanti, E.S.B, S.M. de Morais, A.M.A. Lima, and E.W.P. Santana. 2004).
Salah satu tanaman yang bermanfaat sebagai pestisida alami adalah jeruk nipis. Jeruk nipis merupakan salah satu tanaman penghasil minyak atsiri yang sebagian besar mengandung terpen, siskuiterpen alifatik, turunan hidrokarbon teroksigenasi dan hidrokarbon aromatik. Komposisi senyawa yang terdapat di dalam minyak atsiri yang dihasilkan dari kulit buah tanaman genus Citrus diantaranya adalah limonen, sitronelal, geraniol, $\beta$ kariofilen dan $\alpha$-terpineol (Calvacanti, E.S.B, S.M. de Morais, A.M.A. Lima, and E.W.P. Santana. 2004, Chutia, M., D.P. Bhuyan, M.G. Pathak, T.C. Sarma and P. Buroah. 2009).

Berdasarkan uraian di atas, penulis melakukan penelitian mengenai pemanfaatan kulit buah jeruk nipis (Citrus aurantifolia) sebagai larvasida nyamuk Aedes aegypti instar III.

\section{METODOLOGI PENELITIAN}

Penelitian ini dilaksanakan pada bulan Maret sampai Juli 2015 di Laboratorium Parasitologi Fakultas Ilmu Kesehatan Universitas Maarif Hasyim Latif Sidoarjo. Lokasi pengambilan sampel kulit buah jeruk nipis adalah di warung-warung penjual soto dan sate di daerah sepanjang.

Alat-alat yang digunakan dalam penelitian ini adalah pisau, wadah plastik, neraca digital, rotavapor, pipet skala, labu ukur $100 \mathrm{ml}$, pinset, pipet pasteur, beaker glass, toples, kain kasa, gelas plastik kertas label, spidol. Bahan-bahan yang digunakan dalam penelitian ini adalah larva nyamuk Aedes aegypti instar III yang diperoleh dari laboratorium Entomologi Dinas Kesehatan Provinsi Jawa Timur, kulit jeruk nipis, ethanol $70 \%$ dan aquadest.

Penelitian ini merupakan penelitian eksperimen laboratorium dengan menggunakan pola Rancangan Acak Lengkap (RAL) 8 x 8 dengan 4 kali ulangan. Perlakuan dalam penelitian ini yaitu $\mathrm{K}_{0}$ (kontrol negatif), $\quad \mathrm{K}_{1} \quad$ (konsentrasi ekstrak 1\%), $\mathrm{K}_{2}$ (konsentrasi ekstrak 2\%), $\mathrm{K}_{3}$ (konsentrasi ekstrak $3 \%$ ), $\mathrm{K}_{4}$ (konsentrasi ekstrak 4\%), $\mathrm{K}_{5}$ (konsentrasi ekstrak 5\%), $\mathrm{K}_{6}$ (konsentrasi ekstrak 6\%) dan $\mathrm{K}_{7}$ (konsentrasi ekstrak 7\%), $\mathrm{W}_{1}$ (inkubasi 30 menit), $\mathrm{W}_{2}$ (inkubasi 60 menit), $\mathrm{W}_{3}$ (inkubasi 90 menit), $\mathrm{W}_{4}$ (inkubasi 120 menit), $\mathrm{W}_{5}$ (inkubasi 180 menit), $\mathrm{W}_{6}$ 
(inkubasi 240 menit), $\mathrm{W}_{7}$ (inkubasi 300 menit) dan $\mathrm{W}_{8}$ (inkubasi 1440 menit).

Prosedur kerja pada penelitian ini dimulai dengan pembutan ekstrak kulit jeruk nipis. Setelah kulit buah jeruk nipis terisah dari buahnya, kemudian dikeringkan dengan menggunakan mesin pengering untuk mempercepat proses pengeringan hingga kadar air berkurang dan mencapai $10 \%$. Kulit buah jeruk nipis yang sudah kering dihaluskan dengan menggunakan blender sampai terbentuk serbuk. Serbuk kulit buah jeruk nipis dimasukkan ke dalam toples kaca dan direndam (maserasi) dengan ethanol $\left(\mathrm{C}_{2} \mathrm{H}_{5} \mathrm{OH}\right) 70 \%$ selama $2 \times 24$ jam dengan sesekali diaduk agar larutan tercampur rata. Kemudian disaring dengan menggunakan kain kasa untuk didapatkan maserasi yang agak jernih dan ditampung pada beaker glass. Filtrat yang diperoleh diuapkan dengan menggunakan rotavapor pada suhu $80^{\circ} \mathrm{C}$ hingga seluruh pelarut ethanol hilang dan hanya didapatkan hasil ekstrak murni kental. Untuk selanjutnya bahan ekstrak kental tersebut diformulasikan dengan menambahkan pengencer atau air sebagai pelarut.

Ekstrak kulit buah jeruk nipis dipipet masingmasing $1 \mathrm{ml}, 2 \mathrm{ml}, 3 \mathrm{ml}, 4 \mathrm{ml}, 5 \mathrm{ml}, 6 \mathrm{ml}$ dan $7 \mathrm{ml}$ dan dimasukkan dalam labu ukur 100 ml, kemudian diaddkan dengan aquadest sapai tanda batas, sehingga larutan tersebut mempunyai konsentrasi $1 \%, 2 \%, 3 \%, 4 \%, 5 \%, 6 \%$ dan $7 \%$.

Uji larva nyamuk Aedes agypti dilakukan dengan cara menyiapkan 7 buah gelas plastik yang diberi label $\mathrm{K}_{1}, \mathrm{~K}_{2}, \mathrm{~K}_{3}, \mathrm{~K}_{4}, \mathrm{~K}_{5}, \mathrm{~K}_{6}$ dan $\mathrm{K}_{7}$ dan masing-masing gelas tersebut dimasukkan $100 \mathrm{ml}$ air dan ekstrak kulit buah jeruk nipis sesuai dengan konsentrasi yang tertera pada label serta 1 buah gelas plastik yang diberi label $\mathrm{K}_{0}$ yang berisi $100 \mathrm{ml}$ air saja. Setiap konsentrasi dilakukan pengulangan sebanyak 6 kali ulangan. Setiap gelas dimasukkan 25 ekor larva nyamuk Aedes aegypti instar III, termasuk kontrol dan tanpa diberi makanan. Data dikumpulan dengan cara menghitung jumlah larva yang mati selama beberapa variasi waktu $\left(\mathrm{W}_{1}-\mathrm{W}_{8}\right)$ pada masing-masing gelas perlakuan.

Setelah semua data didapatkan, data dianalisis menggunakan analisis probit untuk menentukan nilai $\mathrm{IC}_{50}$ untuk mengetahui daya bunuh ekstrak kulit jeruk nipis terhadap kematian larva.

\section{HASIL DAN PEMBAHASAN}

\section{A. Hasil}

Hasil pengamatan dan perhitungan jumlah kematian larva nyamuk Aedes aegypti setelah diberi perlakuan dengan berbagai variasi konsentrasi ekstrak kulit buah jeruk nipis dan dengan variasi waktu disajikan pada tabel berikut :

\section{Tabel 1. Rerata kematian larva nyamuk Aedes aegypti instar III pada perlakuan dengan berbagai variasi konsentrasi dan varian waktu}

\begin{tabular}{ccccccccc}
$\begin{array}{c}\text { Waktu } \\
\text { (menit) }\end{array}$ & \multicolumn{7}{c}{ Rata-rata larva kematian larva pada konsentrasi } \\
\cline { 2 - 9 } & 0 & $1 \%$ & $2 \%$ & $3 \%$ & $4 \%$ & $5 \%$ & $6 \%$ & $7 \%$ \\
\hline 30 & 0 & 0 & 0 & 0 & 1 & 2 & 2 & 4 \\
60 & 0 & 1 & 1 & 2 & 3 & 4 & 5 & 5 \\
90 & 0 & 1 & 1 & 2 & 3 & 4 & 6 & 7 \\
120 & 0 & 1 & 1 & 2 & 3 & 4 & 6 & 7 \\
180 & 0 & 1 & 1 & 3 & 3 & 5 & 8 & 8 \\
240 & 0 & 1 & 2 & 3 & 5 & 6 & 8 & 9 \\
300 & 0 & 2 & 2 & 4 & 5 & 7 & 8 & 11 \\
1440 & 0 & 5 & 5 & 7 & 15 & 18 & 25 & 25 \\
\hline
\end{tabular}

Dari data di atasSelanjutnya dilakukan analisis probit dengan tingkat kepercayaan $95 \%$ untuk endapatkan nilai $\mathrm{IC}_{50}$ pada setiap varian waktu. Hasil analisis probit disajikan pada Tabel 2. 
Tabel 2. Data $\mathrm{IC}_{50}$ hasil Probit Analisis berdasarkan parameter waktu

\begin{tabular}{ccc}
\hline No & Waktu (menit) & $\mathrm{IC}_{50}(\%)$ \\
\hline 1 & 30 & 11,324 \\
2 & 60 & 9,808 \\
3 & 90 & 9,556 \\
4 & 120 & 9,556 \\
5 & 180 & 8,564 \\
6 & 240 & 8,257 \\
7 & 300 & 7,853 \\
8 & 1440 & 3,419
\end{tabular}

Dari data di atas dapat diketahui bahwa konsentrasi yang paling efektif dalam membunuh

\section{B. Pembahasan}

Dari hasil pengamatan dan perhitungan jumlah larva nyamuk Aedes aegypti yang mati setelah diberi perlakuan dengan ekstrak kulit buah jeruk nipis dengan konsentrasi $1 \%, 2 \%, 3 \%, 4 \%, 5 \%, 5 \%$ dan $7 \%$ dapat diketahui bahwa pada konsentrasi 1\%, 2\% dan 3\% mengalami kematian berturut-turut, yaitu sebanyak 4, 5, 6 larva. Pada konsentrasi 4\% mengalami kematian sebanyak 14 larva, 5\% mengalami kematian sebanyak 18 larva, serta pada konsentrasi $6 \%$ dan $7 \%$ mengalami kematian sebanyak 25 larva setelah perlakuan selama 1440 menit (24 jam).

Pada umumnya kulit buah jeruk nipis sudah dimanfaatkan dalam bidang kecantikan dan kesehata. Kandungan minyak atsiri yang terdapat dalam kulit jeruk dapat digunakan sebagai obat herbal. Minyak atsiri yang terkandung dalam kulit buah jeruk nipis terdiri dari beberapa senyawa, yaitu limonen $\quad(33,33 \%), \quad \beta$-pinen $\quad(15,85 \%), \quad$ sitral $(10,54 \%)$, neral $(7,94 \%), \gamma-$ terpinen $(6,80 \%), \alpha$ farnesen $\quad(4,14 \%), \quad \alpha$-bergamoten $\quad(3,38 \%)$, $\beta$-bisabolen $(3,05 \%)$, $\alpha$-terpineol $(2,98 \%)$, linalol $(2,45 \%)$, sabinen $(1,81 \%)$, $\beta$-elemen $(1,74 \%)$, nerol $(1,52 \%), \alpha$-pinen $(1,25 \%)$, geranil asetat $(1,23 \%), 4-$ terpinol $(1,17 \%)$, neril asetat $(0,56 \%)$ dan trans- $\beta$ osimen (0,26\%) (Gunawan dan Mulyani. 2004).

Limonen atau limonoid merupakan salah satu senyawa minyak atsiri yang berpotensi sebagai larvasida. Kandungan bahan aktif pada kulit jeruk nipis yang memberikan efek larvasida, yaitu limonoid yang bekerja menghambat pergantian kulit pada larva. Sebagai racun perut, limonoid dapat masuk ke dalam tubuh larva nyamuk Aedes aegypti.
50\% larva nyamuk Aedes aegypti adalah 3,419\% dalam waktu 1440 menit

Masuk ke pencernaan melalui rendaman konsentrasi ekstrak yang termakan. Insektisida akan masuk ke organ pencernaan serangga dan diserap oleh dinding usus kemudian beredar bersama darah yang akan mengganggu metabolisme tubuh nyamuk sehingga akan kekurangan energi untuk aktivitas hidupnya, sehingga mengakibatkan larva nyamukkejang dan akhirnya mati (Murdani, R. 2014, Devy, Yulianti dan Andrini. 2010).

Dari hasil penelitian yang dilakukan Anjar (2014) dengan menggunakan ekstrak buah pare (Momordica charantia L) dan penelitian yang dilakukan oleh Iryanto (2013) dengan menggunakan ekstrak daun jeruk purut (Citrus hystrix) nampak bahwa kedua ekstrak tersebut juga dapat digunakan sebagai larvasida. Ujimenggunakan ekstrak daun jeruk purut (Citrus hystrix)pada dosis $25 \mu 1$ dan 50 $\mu 1$ secara berurutan dapat membunuh 10 larva dan 25 larva dalam waktu 24 jam, sedangkan ekstrak kulit jeruk nipis (Citrus aurantifolia) pada konsentrasi 5\% dan 6\% secara berurutan dapat membunuh sebanyak 18 larva dan 25 larva dalam waktu 24 jam. Pada uji larvasida menggunakan ekstrak buah pare (Momordica charabtia L) dengan konsentrasi yang sama, yaitu 5\% dapat membunuh larva sebanyak 4 larva dalam waktu 24 jam.

Penggunaan kulit jeruk nipis (Citrus aurantifolia) dapat diaplikasikan di masyarakat sebagai alternatif dalam pengendalian vektor penyebab demam berdarah dengue (DBD). Pemakaian kulit buah jeruk nipis sebagai larvasida lebih aman, hal ini disebabkan selain dapat membunuh larva nyamuk Aedes aegypti, juga ramah lingkungan, tidak menimbulkan bahaya, serta 
memiliki keuntungan lain yaitu mudah didapatkan dan dapat mengurangi jumlah limbah/sampah organik, karena selama ini kulit buah jeruk nipis (Citrus aurantifolia) hanya dibuang begitu saja tanpa dimanfaatkan lebih lanjut.

\section{KESIMPULAN}

Berdasarkan penelitian yang telah dilakukan, dapat disimpulkan bahwa :

1. Ekstrak kulit buah jeruk nipis (Citrus aurantifolia) memiliki kemampuan dalam membunuh larva nyamuk Aedes aegypti instar III

2. Konsentrasi efektif ekstrak kulit jeruk nipis (Citrus aurantifolia) yang dapat membunuh 50\% $\left(\mathrm{IC}_{50}\right)$ larva nyamuk Aedes aegypti adalah 3,419\% dalam waktu 24 jam

\section{UCAPAN TERIMAKASIH}

Penulismengucapkan terimakasih kepada semua pihak yang telah membantu selama penelitian ini berlangsung, terutama para staf laboratorium Parasitologi, Fakultas Ilmu Kesehatan, Universitas Maarif Hsyim Latif Sidoarjo.

\section{DAFTAR PUSTAKA}

[1] Aradilla, A.S. 2009. Uji Efektivitas Larvasida Ekstrak Ethanol Daun Mimba (Azadirachta indica) terhadap Larva Aedes aegypti. Skripsi. FK UNDIP. Semarang.

[2] Astarini, N.P.F. 2010. Minyak Atsiri Kulit Buah Citrus grandis, Citrus aurantium (L.) dan Citrus aurantifolia sebagai Senyawa Antibakteri dan Insektisida. http://digilib.its.ac.id/public/ITS-

Undergraduate-13463-Paper.pdf (diakses 26 November 2014)

[3] Calvacanti, E.S.B, S.M. de Morais, A.M.A. Lima, and E.W.P. Santana. 2004. Larvacidal Activity of Essential Oils from Brazilian Planta Againts Aedes aegypti L. Mem Inst Oswaldo Cruz. 99(5) : 541-544.

[4] Chutia, M., D.P. Bhuyan, M.G. Pathak, T.C. Sarma and P. Buroah. 2009. Antifungal Activity and Chemical Composition of Citrus reticulata Blanco Essential Oil Against Phytogens from Morth East India. J.Food Science and Technology. 42 : 777-780.
[5] Dantje, T.S., 2009. Entologi Kedokteran. Andi Offset. Yogyakarta.

[6] Devy, Yulianti dan Andrini. 2010. Kandungan Flavonoid dan Limonoida pada Berbagai Pertumbuhan Tanaman Jeruk Kalamondin (Citrus mitis Blanco) dan Purut (Citrus hystrix Dc.). Balai Penelitian Buah dan Jeruk Subtropika. Batu.

[7] Gunawan dan Mulyani. 2004. Ilmu Obat Alam. Jilid 1. Penebar Swadya. Jakarta.

[8] Haditomo, I. 2010. Efek Larvasida Ektrak Daun Cengkeh (Syzygium aromaticum L.) Terhadap Aedes aegypti. http://eprints.uns.ac.id/7308/1/1228031072010 11151.pdf (diakses 18 Oktober 2014).

[9] Murdani, R. 2014. Keefektivan Daya Bunuh Ekstrak Daun Jeruk Nipis (Citrus aurantifolia) terhadap Kematian Larva Nyamuk Aedes aegypti instrar III.

[10] Novizan. 2002. Membuat dan Memanfaatkan Pestisida Ramah Lingkungan. Agro Media Pustaka. Jakarta. 37-40.

[11] Pratama, B.A. 2009. Pemanfaatan Ekstrak Daun Pandan Wangi (Pandanus amaryllifolius Rxb.) sebagai Larvasida Alami.http://publikasiilmiah.ums.ac.id/bitstrea $\mathrm{m} /$ handle/123456789/2071/2.pdf? sequence $=1$ (diakses 26 November 2014).

[12] Pratiwi, A. 2013. Studi Deskriptif Penerimaan Masyarakat Terhadap Larvasida Alami. http://lib.unnes.ac.id/20019/1/6450408054.pdf (diakses 30 Oktober 2014).

[13] Susana, D. 2003. Potensi Daun Pandan Wangi Untuk Membunuh Larva Nyamuk Aedes aegypti. http://ejournal.litbang.depkes.go.id/index.php/j ek/article/viewFile/1396/pdf (diakses 18 Oktober 2014).

[14] Wijaya, L.A. 2008. Daya Bunuh Ekstrak Biji Kecubung (Datura metel) Terhadap Larva Aedes aegypti. FK-UNS. Surakarta. 